\section{Soil Amendments and Soil Profiling Impact on Macadamia Growth and Yield Performance}

\author{
Russell Galanti ${ }^{1}$ and Alyssa Cho \\ Department of Tropical Plant and Soil Science, University of Hawaii at \\ Manoa, Komohana Research and Extension Center, 875 Komohana Street, \\ Hilo, HI 96720

\section{Amjad Ahmad and Theodore Radovich \\ Department of Tropical Plant and Soil Science, University of Hawaii at Manoa, St. John Plant Science Laboratory, 3190 Maile Way, Honolulu, HI 96822}

Additional index words. Macadamia integrifolia, mulch, biochar, soil management, organic matter

\begin{abstract}
Macadamia (Macadamia integrifolia, Maiden \& Betche) orchard management in Hawaii can result in the loss of organic matter and soil degradation. The objective of this study was to determine the effects of macadamia husk mulch, husk mulch combined with biochar, husk mulch combined with effective microorganisms (EM), soil profiling, and wood chip mulch on yield, nut quality, root growth, and SPAD values during a 1-year study of mature macadamia orchards at two locations in Hawaii. A partial cost-benefit analysis was performed to compare the costs and yield benefits of each treatment. Soil profiling resulted in higher yields than any other treatment, at a mean of $86.6 \mathrm{~kg}$ wet-inhusk per tree. No treatments significantly affected nut quality or dry kernel weight. Nut quality was affected by harvesting time, with the earliest harvesting (Aug. 2017) period resulting in the highest recovery rate of number 1 grade kernels $(33 \%)$. SPAD values increased with the husk mulch combined with EM $(6.5 \%)$ treatment and soil profiling treatment (6.9\%). Husk combined with EM caused an $87 \%$ increase in total root biomass during the study period due to increased proteoid root biomass. The soil profiling treatment had the second lowest estimated cost per hectare and had the highest estimated partial profit per hectare. Soil profiling is a destructive management practice and should be used judiciously until its long-term effects on orchard health are studied. The inoculation of EM or sugar signaling may have been responsible for the proliferation of proteoid roots with the husk mulch and EM treatment.
\end{abstract}

Macadamia (Macadamia integrifolia, Maiden \& Betche) nut production is estimated to be a 22.2 million kilogram, $\$ 53.2$ million industry in Hawaii (USDA, 2018), and the largest macadamia production occurs in the United States. Current management practices during harvesting include the removal of all loose organic matter that has accumulated as litter from vegetation from the orchard floor to facilitate nut pick-up, which is a practice that can lead to soil degradation (Dalby et al., 2010). Similar intensive agricultural management of systems with soil disturbance and continuous monocrop systems have resulted in reduced soil organic matter (SOM) (Liu et al., 2006). SOM acts as a source of inorganic nutrients such as nitrogen (N) and microbial food, and ion exchange is a factor in root development (Allison, 1973) and is essential in maintaining soil quality in continuous cropping systems (Reeves, 1997). Organic sources of $\mathrm{N}$ are lost during harvest.

Received for publication 17 Sept. 2018. Accepted for publication 27 Dec. 2018.

${ }^{1}$ Corresponding author. E-mail: rgalanti@hawaii. edu.
Every $100 \mathrm{~kg}$ of macadamia harvested also removes $\approx 405 \mathrm{~g}$ of $\mathrm{N}$ that was partitioned in the nut (Nagao and Hirae, 1992). It has been suggested that leaves are a significant $\mathrm{N}$ sink (Fletcher et al., 2009) and storage pool (Huett et al., 2001; Stephenson and Cull, 1986) for macadamia. The removal of these leaves from the agroecosystem can lead to a significant loss of $\mathrm{N}$ from the macadamia cropping system.

Fertilizer is required to maintain nutrient concentrations at the recommended levels in macadamia orchards for optimal production (Nagao and Hirae, 1992). Improper use of synthetic fertilizers has been linked to environmental degradation. Before the 1920s, atmospheric $\mathrm{N}_{2} \mathrm{O}$ levels did not commonly exceed $280 \mathrm{ppb}$. Levels have increased, mainly due to agriculture, to a new high of $328 \mathrm{ppb}$ (Environmental Protection Agency, 2016). Excessive use of fertilizer to ensure nutrient pollution and promoting eutrophication and harmful algal blooms downstream (Heisler et al., 2008) while not improving overall production (Stephenson and Gallagher, 1989). Stakeholders in Hawaii consider replacing imported fertilizers with locally produced proper yields can lead to runoff, causing organic sources to be a high priority, and sourcing local inputs is ranked third on their list of barriers to increasing local crop production (Ahmad et al., 2016; Radovich et al., 2009).

Sources of local soil amendments for macadamia are the remaining husk, shell, and wood chips from harvest, pruning, and tree removal. Mulches can improve indicators related to soil health that contribute to tree growth and yield. Gao et al. (2009) observed an increase of $53.6 \%$ in nutrient use efficiency in wheat with straw mulch and a 36\% increase with no mulch after 3 years. Wood chip mulch for tea olive (Osmanthus fragrans) improved root activity by $24.5 \%$ and chlorophyll content by $6.47 \%$ compared with no mulch (Xue et al., 2016). Porter et al. (2005) observed increased macadamia root growth and yield from macadamia husk mulch applications compared with a control, but they indicated that a lag period of 2 to 3 years may be necessary to produce results. A similar length of time was also necessary to observe increased leaf $\mathrm{N}$ concentrations in 'Giles' pecan (Carya illinoiensis) (Smith et al., 2000). However, after 18 months, macadamia husk compost increased microbial biomass by $300 \%$ compared with bare soils for macadamia (Cox et al., 2004), and it has been noted that increased microbial activity assists $\mathrm{N}$ cycling and availability for plants (Raviv, 1998).

Additional and novel soil amendments are now being used for macadamia production and should be assessed for efficacy. Biochar is a recently available option for farmers in Hawaii. Biochar can have a varied impact on yield; a meta-study conducted by Jeffery et al. (2011) found that in 51 studies that evaluated the effects of biochar, a decrease as much as $28 \%$ and an increase as much as $100 \%$ in yield can occur. Biochar can also be a direct source of available plant $\mathrm{N}$ (Zheng et al., 2013), can be used to reduce $\mathrm{N}$ losses (Clough et al., 2013), and can change soil properties that impact nutrient availability and plant growth and yield (Baiamonte et al., 2014; Laird et al., 2010; Liang et al., 2010). Biochar application methods usually involve the incorporation of biochar in the soil; however, in perennial cropping systems where the soil is not tilled, the surface application of biochar occurs.

Effective microorganisms (EM) are part of a novel method of organic management used in Hawaii, and specifically in the culturing of indigenous microorganisms (IMO). IMO comprise nonselective naturally occurring microorganisms that are usually collected by placing steamed rice outdoors in the agroecosystem. Microorganisms colonize this rice and are multiplied using a carbohydrate source, water, and growth medium. This culture is diluted with water and sprayed onto plants and soil in production systems. These cultures of unknown populations are difficult to replicate; however, a product called EM- $1{ }^{\circledR}$ (Terra Granix, Alto, TX), developed by Teruo Higa, can be used to emulate indigenous microorganism treatments. EM-1 ${ }^{\circledR}$ 
Table 1. Baseline soil properties of soils under two sites in macadamia orchards in Kapa'au, HI.

\begin{tabular}{lcc}
\hline Property & Site 1 & Site 2 \\
\hline Series & Ainakea & Kohala \\
Texture & Silty clay loam & Silty clay \\
Bulk density & $0.88 \mathrm{~g} / \mathrm{cm}$ & $0.98 \mathrm{~g} / \mathrm{cm}$ \\
Water-holding & 25.6 & 21.2 \\
$\quad$ capacity (\%) & & \\
Carbon (\%) & 6.04 & 5.75 \\
pH & 5.65 & 5.56 \\
\hline
\end{tabular}

comprises Lactobacillus casei, a lactic acid bacterium (LAB). LAB functions with soil amendments by consuming carbohydrates in biomass, thereby speeding the decomposition rates. $\mathrm{LAB}$ can increase yields and plant growth. Olle and Williams (2013) noted yield increases of $43 \%$ in peas in Europe. Similar studies have noted increases in the yield (Iwaishi, 2000; Khaliq et al., 2006) of rice and cotton, but few studies of the effects of EM on orchard crops have been performed, and no studies have addressed the effects of EM on macadamia production.

An additional novel soil amendment practice that has been implemented in Australian macadamia orchards and in Hawaii is soil profiling, which is also called fraze mowing; this practice is generally used for turfgrass management. Soil profiling is defined as the mechanical removal and displacement of $0.5 \mathrm{~cm}$ to $5 \mathrm{~cm}$ of soil surface. The soil is removed from the interrows of macadamia orchards and deposited into the rows directly under the center of the macadamia canopies. However, the effects of soil profiling in Hawaii have not been studied.

The objective of this study was to compare the effects of these new and novel soil amendment treatments on yield and quality, leaf SPAD values, and root growth in mature macadamia orchards. The soil amendment treatments were expected to increase SPAD values, root growth, and potential yield compared to the control treatment.

\section{Materials and Methods}

Study site. Field experiments were conducted between Aug. 2016 and Mar. 2018 using a mature macadamia orchard located in Kapa'au, Hawaii (lat. $20^{\circ} 12^{\prime} \mathrm{N}$, long. $\left.155^{\circ} 47^{\prime} \mathrm{W}\right)$. Two soil orders are present in this region, andisol and inceptisol. The two sites were selected based on the uniformity of the macadamia variety. Site 1 was certified organic in 2012, and it is managed organically. Site 2 is managed conventionally. Average monthly temperatures ranged from $20.7^{\circ} \mathrm{C}$ to $24.3^{\circ} \mathrm{C}$. The average annual rainfall is $1413.2 \mathrm{~mm}$, with monthly averages ranging from $71.6 \mathrm{~mm}$ to $177.4 \mathrm{~mm}$ (Giambelluca et al., 2013). Soil properties for each site are listed in Table 1. The macadamia cultivar used in the experiment was Hawaii agricultural experiment station (HAES) accession 508 'Kakea', which is a scion grafted onto seedlings of the cultivar HAES 660 'Keaau'.

Experimental design. The experiment was a randomized complete block design with

Table 2. Soil amendment treatments application methods, equipment used, and application rates applied to macadamia trees in Mar. 2017 in Kapa'au, HI.

\begin{tabular}{llc}
\hline Amendment & \multicolumn{1}{c}{ Application rate } & Method \\
\hline Control $^{\mathrm{z}}$ & \multicolumn{1}{c}{-} & - \\
Macadamia husk mulch & $495 \mathrm{~m}^{3} \cdot \mathrm{ha}^{-1}, 5-\mathrm{cm} \mathrm{depth}$ & Compost spreader \\
Macadamia husk mulch + biochar & Mulch: $495 \mathrm{~m}^{3} \cdot \mathrm{ha}^{-1}, 5-\mathrm{cm}$ depth & Compost spreader \\
& Biochar: $49.5 \mathrm{~m}^{3} \cdot \mathrm{ha}^{-1}, 0.5-\mathrm{cm}$ depth & \\
Macadamia husk mulch $+\mathrm{EM}^{\mathrm{y}}$ & Mulch: $495 \mathrm{~m}^{3} \cdot \mathrm{ha}^{-1}, 5-\mathrm{cm} \mathrm{depth}$ & Compost spreader, \\
& $\mathrm{EM}-3500-\mathrm{L} \cdot \mathrm{ha}^{-1}, 1: 1: 1000$ & 100-L sprayer \\
Soil profile & $\mathrm{EM}: \mathrm{Molasses}_{2} \mathrm{O}$ & \\
Wood chip mulch & $247.5 \mathrm{~m}^{3} \cdot \mathrm{ha}^{-1}, 2.5-\mathrm{cm}$ depth & Soil profiler
\end{tabular}

${ }_{\mathrm{z}}^{\mathrm{A}}$ pplication rate and method are not applicable for control plots receiving no treatment.

${ }^{\mathrm{y}} \mathrm{EM}=$ effective microorganisms.

four replicates (blocks). In each block, the six treatments were randomly assigned to plots. Six treatments were applied in Mar. 2017 to plots consisting of four trees in a linear arrangement, with a total of 192 trees. During the experiment, all management practices were uniform among all blocks. Several treatments were evaluated, including 1) no treatment (control), 2) macadamia husk mulch (husk), 3) macadamia husk mulch with macadamia shell biochar (husk plus biochar), 4) macadamia husk mulch with effective microorganisms (husk plus EM), 5) soil profiling, and 6) wood chip mulch. Treatments and application rates can be found in Table 2. The husk of the previous season was developed into partially decomposed mulch by forming it into windrows at the end of the harvest season (Feb. 2016). Wood chip mulch was sourced from a neighboring farm and consisted of multiple species of trees. Biochar was sourced from Pacific Biochar (Pahoa, HI). The EM product was sourced from Terra Granix (Alto, TX). Soil amendments were applied to plots in Mar. 2017. Baseline properties of all solid mulch inputs are presented in Table 3.

Yield and quality sampling. Tree yield as wet-in-husk weight was collected during three harvest sampling times in Aug. 2017, Oct. 2017, and Dec. 2017 for all individual trees. During each sampling period, a subsample including 20 nuts per plot was collected. Total weights were measured for wet-in-husk and wet-in-shell. Nuts were dried to $10 \%$ moisture according to the procedures of Wall and Gentry (2007). Total dry shell weight was measured. Individual nuts were weighed to determine dry shell weight and kernel weight. They were assessed for oil content using a float test, assessed for wholeness of the kernel, and assessed for defects. Kernels that float and have no defects are considered number 1 (No. 1) grade. The equation to determine the No. 1 kernel recovery rate (KRR) is as follows: [(Weight of total No. 1 grade kernels/Weight of total dried nuts-in-shell) $\times 100$ ]. This equation provides the total weight of saleable kernel compared to the weight of dry-in-shell nuts.

SPAD value sampling. A total of 15 measurements were performed using two randomly selected trees in each plot, resulting in 30 measurements per plot using a Minolta SPAD-502 chlorophyll meter (Konica Minolta, Osaka, Japan). The measurement
Table 3. Baseline properties of solid mulch inputs applied to macadamia trees in Mar. 2017 in Kapa'au, HI $(\mathrm{N}=3)$.

\begin{tabular}{lclcc}
\hline Input & $\mathrm{N}(\%)$ & $\mathrm{C}(\%)$ & $\mathrm{pH}$ & $\mathrm{EC}(\mathrm{mS} / \mathrm{cm})$ \\
\hline Wood chip & 0.31 & 45.36 & 6.69 & 1.68 \\
Husk & 1.10 & 46.6 & 7.68 & 0.98 \\
Biochar & 0.31 & 61.17 & 9.50 & 10.5 \\
\hline
\end{tabular}

amount followed protocols for tissue sampling of macadamia (Hirae, 1976). The leaf selection criterion was mature, healthy leaves on the second whorl from the mature (no longer green and not flushing) tip of a branch exposed to full sun. Measurements were performed near the midpoint of the midrib of each leaf sample. Samples were taken from the same trees every month before the treatments were applied from Mar. 2017 until Feb. 2018.

Root growth sampling. Root samples were collected in Feb. 2017, June 2017, and Feb. 2018. Mulch was moved from the soil surface before collection. A soil sample with a $10-\mathrm{cm}$ depth and 2-cm width was collected using a soil corer $\left(31.42 \mathrm{~cm}^{3}\right)$ from two locations in each plot (from the interrow and within the row). Samples were collected at the same distance as the drip line of the canopy of the individual tree. Soil samples were soaked in water for $30 \mathrm{~min}$. The solution was drained into a mesh sieve measuring $250 \mu \mathrm{m}$. Roots were separated, rinsed, and placed back in a clean water solution. The process was repeated until roots were free of debris and soil. The roots were placed in metal drying boats and dried at $70^{\circ} \mathrm{C}$ for $72 \mathrm{~h}$. Then, roots were weighed to determine the dry weight/volume. Proteoid roots were separated from the total root sample and weights were recorded.

Soil sampling. Soil samples were collected in Aug. 2016 before treatment application, in June 2017, and in Feb. 2018. Samples were collected from the row and interrow in each plot. Mulch was moved from the soil surface before collecting samples. A sample of soil was collected using a hand trowel from the surface of the soil down to a depth of $5 \mathrm{~cm}$. Soil samples were homogenized and held at $0{ }^{\circ} \mathrm{C}$ after collection. Total $\mathrm{N}$ was measured by gas chromatography. Samples were dried for $24 \mathrm{~h}$ at $105^{\circ} \mathrm{C}$ and sieved through an $833-\mu \mathrm{m}$ sieve. Samples were analyzed using a Costech 4010 elemental analyzer at the University of Hawaii at Hilo Analytics Laboratory. 
Partial cost-benefit analysis. A partial cost-benefit analysis was conducted using cost information from the farmer. Material and application costs were estimated per hectare for all mulch treatments after adjusting for hourly application rates. Hourly equipment depreciation was estimated using annual depreciation divided by estimated hours of annual use. Yields per tree were estimated for the wet-in-shell weight by using the average wet-in-husk harvest data according to treatment and converting it to wet-in-shell by using wet-in-shell subsample data averaged according to treatment. Yields were converted to yield-per-hectare estimations using mean tree yields for treatments and multiplying by an estimated number of trees per hectare if planted with spacing of $15^{\prime} \times 30^{\prime}$. The weights per hectare were adjusted based on the average KRR for the treatments. When purchasing macadamia, processors adjust the weight and amount paid based on the KRR. The industry standard in Hawaii for purchasing macadamia is based on $30 \%$ kernel recovery. Yields with a kernel recovery more or less than $30 \%$ resulted in an adjusted weight based on confidential calculations used by macadamia processors. These calculations were used to adjust the weights for the yields in this study. The price per pound was obtained from the United States Department of Agriculture (USDA) final season estimates (USDA, 2017) and converted to kilograms. The profit was based on a partial cost estimate using only the costs of applying the treatment and the soil amendment cost. All other costs were even among treatments. The profit is not meant to be an estimate of what the actual profit would be due to the exclusion of additional operating costs.

Statistical analysis. All data were subjected to analysis using JMP Pro version 13.1 (SAS Institute Inc., Cary, NC). Levene's tests were performed to assess equal variance. The Shapiro-Wilks test was used to test for normal distribution. The null hypothesis for equal variance was rejected for total yield $(P=0.0278)$. Data were transformed using $\log _{10}$ transformation. The null hypothesis for equal variance was not rejected after data transformation $(P=0.1138)$. Two-way analysis of variance using mixed-model personality was used to test for effects and interactions, with block included as a random effect. Post hoc Tukey honestly significant difference tests and Student's $t$ tests were performed for comparisons of the means.

\section{Results}

Yield and quality. Treatment affected the total wet-in husk yield per tree (Table 4). The soil profiling treatment had a mean yield of $86.6 \mathrm{~kg}$ (Table 4) per tree and was higher than that of all other treatments, with the exception of the husk treatment $(70.3 \mathrm{~kg} /$ tree $)$. The KRR was unaffected by treatment (Table 4 ). The control had the highest KRR at $31.7 \%$, but it was not statistically significantly different from that of other treatments (Table 4). The sampling period affected overall kernel

Table 4. Mean total wet-in-husk yield per tree, mean kernel recovery rate, and mean dry kernel weight, averaged by treatment, and two-way analysis of variance full factorial reports for significance of effects and interactions for location, month, and treatment for macadamia trees receiving six soil amendment treatments during the 2017-18 harvest season $(\mathrm{N}=32)$.

\begin{tabular}{|c|c|c|c|}
\hline & Mean yield ${ }^{\mathrm{z}}(\mathrm{kg} /$ tree $)$ & Mean kernel recovery (\%) & Mean dry kernel wt (g) \\
\hline \multicolumn{4}{|l|}{ Treatment } \\
\hline Control & $67.6^{\mathrm{a}}$ & $31.7^{\mathrm{NS}}$ & $2.63^{\mathrm{NS}}$ \\
\hline Husk & $70.3^{\mathrm{ab}}$ & 29.7 & 2.68 \\
\hline Husk+biochar & $66.8^{\mathrm{a}}$ & 30.9 & 2.72 \\
\hline Husk $+\mathrm{EM}^{\mathrm{y}}$ & $66.3^{\mathrm{a}}$ & 30.8 & 2.73 \\
\hline Soil profile & $86.6^{\mathrm{b}}$ & 29.9 & 2.73 \\
\hline Wood chip & $60.5^{\mathrm{a}}$ & 30.8 & 2.62 \\
\hline \multicolumn{4}{|l|}{ Source of variation } \\
\hline Location (L) & 0.1806 & 0.1459 & $<0.0001$ \\
\hline Month $(\mathrm{M})^{\mathrm{x}}$ & - & $<0.0001$ & $<0.0001$ \\
\hline Treatment $(\mathrm{T})$ & $0.0002^{\mathrm{w}}$ & 0.4003 & 0.4109 \\
\hline $\mathrm{L} * \mathrm{M}$ & - & 0.0917 & 0.0921 \\
\hline $\mathrm{L} * \mathrm{~T}$ & 0.1074 & 0.9242 & 0.2597 \\
\hline $\mathrm{M}^{*} \mathrm{~T}$ & - & 0.458 & 0.2146 \\
\hline $\mathrm{L} * \mathrm{M} * \mathrm{~T}$ & - & 0.6959 & 0.1188 \\
\hline
\end{tabular}

${ }^{\mathrm{z}}$ Mean separation by Tukey's honestly significant difference method $(P=0.05)$. Means in the same column followed by the matching letter(s) are not significantly different. NS = no significant difference was found among treatments.

${ }^{\mathrm{y}} \mathrm{EM}=$ effective microorganisms.

${ }^{\mathrm{x}}$ Month and month by interactions not applicable to total yield.

${ }^{\text {w } B o l d ~ t e x t ~ i n d i c a t e s ~ a ~ s t a t i s t i c a l l y ~ s i g n i f i c a n t ~ d i f f e r e n c e ~}(P \leq 0.05)$.

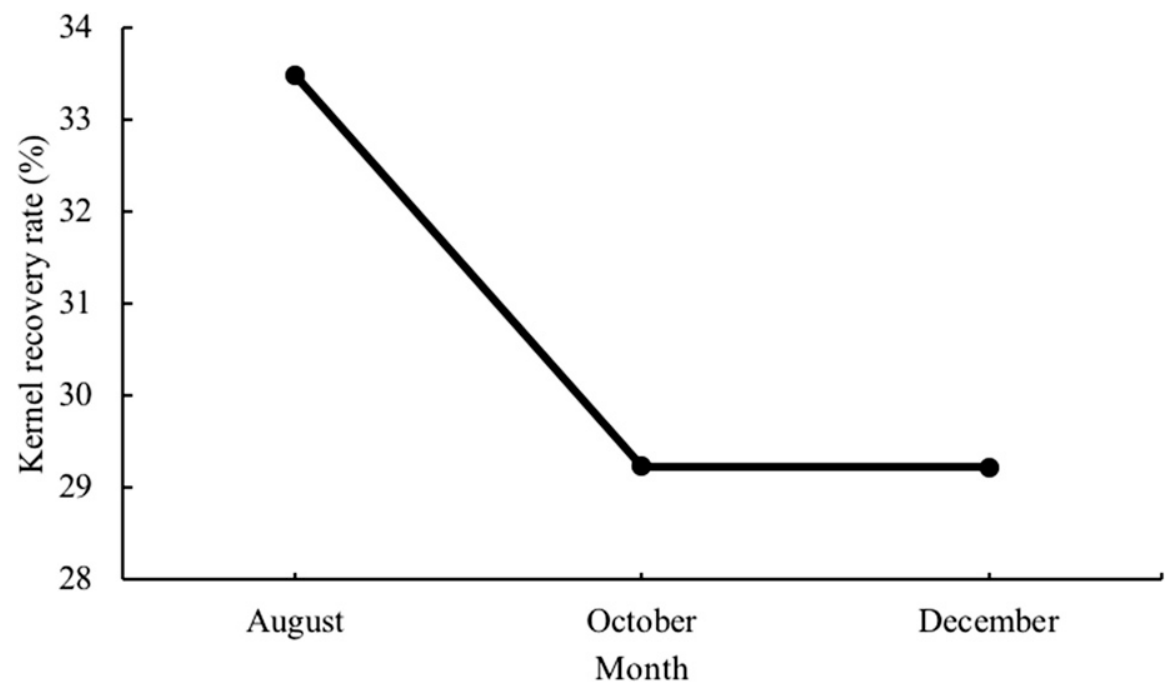

Fig. 1. Mean kernel recovery rate averaged by sampling period for macadamia receiving six soil amendments for the 2017-18 harvest season in Kapa'au HI.

recovery, but there was no interaction with treatment (Table 4). August had a mean KRR of $33 \%$ and was higher than that during the October and December harvests, both of which had a mean KRR of $29.2 \%$ (Fig. 1). The dry kernel weight was similar among treatments (Table 4). Location and month both had effects on dry kernel weights (Table 4). Dry kernel weights were higher for site 2 $(2.81 \mathrm{~g})$ compared with site $1(2.67 \mathrm{~g})$ in August (Fig. 2). They were increased at both sites from the August sampling period to the October sampling period at site $1(2.92 \mathrm{~g})$ and site $2(2.70 \mathrm{~g})$; they were decreased during the December sampling period at site $1(2.53 \mathrm{~g})$ and site 2 (2.48 g) (Fig. 2).

SPAD value. At site 1 , SPAD values did not significantly change from pretreatment to posttreatment for any of the treatments (Table 5). Despite the lack of significant change over the course of 1 year, some treatments did differ from each other in Feb. 2018, which may have led to a wider range of differences between treatments in longer-term studies. The husk, husk plus EM, and wood chip treatments had higher SPAD values than the control (Table 5). In Mar. 2017, results of the husk plus EM treatment and the wood chip treatment were not significantly different from those of the control. Despite the treatments resulting in similar changes in SPAD values, and despite none of the treatments causing a large increase in SPAD values from pretreatment to posttreatment, the husk, husk plus EM, and wood chip treatments successfully increased the SPAD values compared to those of the control at the time of posttreatment. At site 2, SPAD values increased from pretreatment to posttreatment for the husk plus EM and soil profiling treatments (Table 5). Both treatments had an average SPAD value of 50.4 at the Mar. 2017 sampling time; this value increased by 3.3 for the husk plus EM treatment and by 3.5 for the soil profiling 


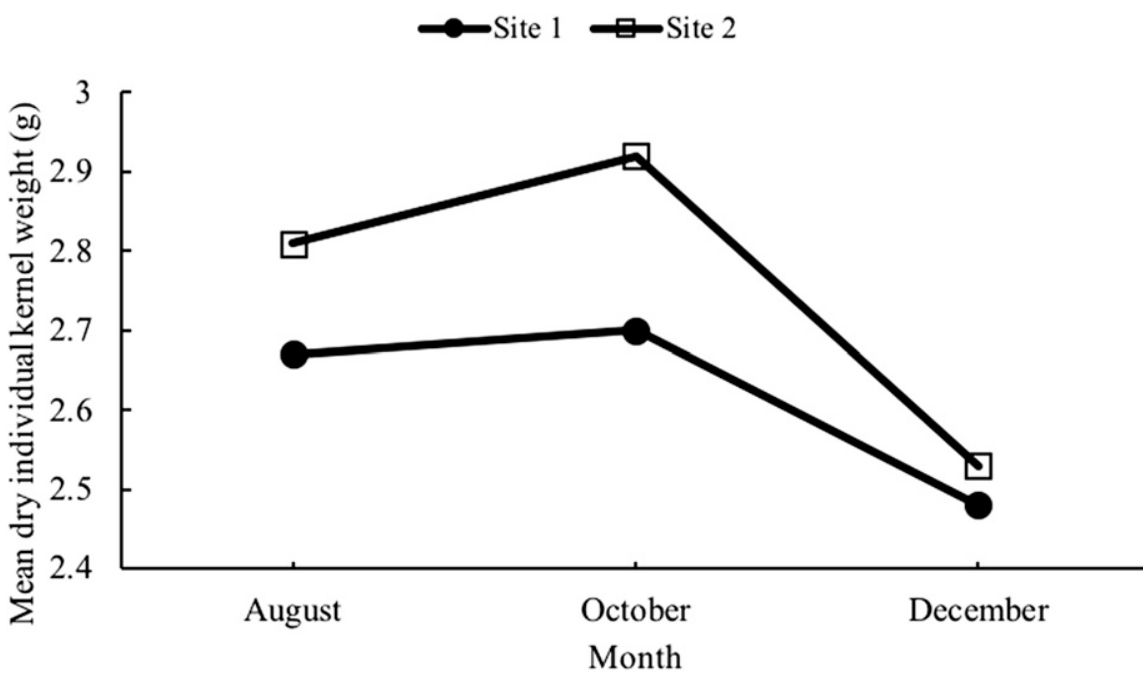

Fig. 2. Mean dry individual kernel weight averaged by location and by month for macadamia receiving six soil amendment treatments for the 2017-18 harvest season in Kapa'au, HI.

Table 5. Mean SPAD values for macadamia trees receiving six soil amendment treatments for the pretreatment sampling time in Mar. 2017 and final sampling in Feb. 2018 and change from pretreatment to final sampling $(\mathrm{N}=16)$ and two-way analysis of variance full factorial reports for the significance of effects and interactions for location, month, and treatment.

\begin{tabular}{lr}
\hline Source of variation & \\
\hline Location $(\mathrm{L})$ & $\mathbf{0 . 0 0 5 9}$ \\
Month $(\mathrm{M})$ & $<\mathbf{0 . 0 0 0 1}$ \\
Treatment $(\mathrm{T})$ & $<\mathbf{0 . 0 0 0 1}$ \\
L*M & $<\mathbf{0 . 0 0 0 1}$ \\
L*T & $<\mathbf{0 . 0 0 0 1}$ \\
$\mathrm{M}^{*} \mathrm{~T}$ & $<\mathbf{0 . 0 0 0 1}$ \\
$\mathrm{L}^{*} \mathrm{M}$ T & $<\mathbf{0 . 0 0 0 1}$
\end{tabular}

Site 1

\begin{tabular}{|c|c|c|c|c|c|c|}
\hline Sampling period & Control & Husk & Husk+biochar & Husk+EM & Soil profile & $\overline{\text { Wood chip }}$ \\
\hline Mar. 2017y & $51.6^{\mathrm{ab}}$ & $55.2^{\mathrm{c}}$ & $51.0^{\mathrm{a}}$ & $52.7^{\mathrm{ab}}$ & $54.0^{\mathrm{bc}}$ & $54.0^{\mathrm{bc}}$ \\
\hline Feb. 2018 & $51.4^{\mathrm{a}}$ & $54.2^{\mathrm{b}}$ & $53.1^{\mathrm{ab}}$ & $54.6^{\mathrm{b}}$ & $53.8^{\mathrm{ab}}$ & $55.5^{\mathrm{b}}$ \\
\hline Change $^{x}$ & -0.2 & -1 & +2.1 & +1.9 & -0.2 & +1.5 \\
\hline Change (\%) & -0.38 & -1.81 & 4.11 & 3.60 & -0.37 & 2.77 \\
\hline \multicolumn{7}{|c|}{ Site 2} \\
\hline & Control & Husk & Husk+biochar & Husk+EM & Soil profile & Wood chip \\
\hline Mar. 2017 & $51.3^{\mathrm{NS}}$ & 50.9 & 51 & 50.4 & 50.4 & 49.5 \\
\hline Feb. 2018 & $51.5^{\mathrm{abc}}$ & $52.8^{\mathrm{abc}}$ & $51.2^{\mathrm{ac}}$ & $53.7^{\mathrm{ab}}$ & $53.9^{b}$ & $51.1^{\mathrm{c}}$ \\
\hline Change & +0.2 & +1.9 & +0.2 & +3.3 & +3.5 & +1.6 \\
\hline Change (\%) & 0.38 & 3.73 & 0.39 & 6.54 & 6.94 & 3.23 \\
\hline
\end{tabular}

${ }^{\mathrm{z}}$ Bold text indicates a statistically significant difference $(P \leq 0.05)$.

${ }^{\mathrm{y}}$ Mean separation by the Tukey's honestly significant difference method $(P=0.05)$. Data are separated by site, and means in the same row in the same site with the matching letter(s) are not significantly different. NS = no significant difference found among treatments.

${ }^{x}$ Bold text indicates a statistically significant difference between Mar. 2017 and Feb. 2018, with $P \leq 0.05$. $\mathrm{EM}=$ effective microorganisms.

treatment. These results suggested that only the husk plus EM and soil profiling treatments significantly increased SPAD values within 1 year at the conventionally managed site.

Total root biomass. Total root biomass was affected by the sampling period, and treatment had an interaction with the sampling period (Table 6). The mixed model suggested a location interaction with treatment; however, post hoc tests suggested no treatment differences between locations. There were almost no significant differences in total root biomass by volume between treatments for all sampling periods, with the exception of Feb. 2018. The husk plus EM treatment resulted in higher total root biomass compared with the wood chip treatment in Feb. 2018 (Table 6). Some treatments did result in in a decrease in proteoid root biomass of $80 \%$, and the control resulted in a small increase of $30 \%$, but these changes were not statistically significant. The husk, husk plus biochar, and soil profiling treatments resulted in increases that were not statistically significant.

Proteoid root proportion. Treatment had an effect on the proportion of samples with proteoid roots, and month had an interaction with treatment (Table 6). The proportion of samples with proteoid root biomass was affected by treatment in Feb. 2018 (Table 6). The mean proportion of samples with proteoid root biomass was significantly higher for the husk plus EM treatment $(87.5 \%)$ than for every other treatment except for the soil profiling treatment (50\%). The husk plus EM and soil profiling treatments both resulted in higher proportions of proteoid roots compared with the control (6.3\%). The control and wood chip treatments resulted in decreases in the proportions of proteoid roots, but these decreases were not statistically significant.

Soil nitrogen. Mean total soil N (\%) was affected by the sampling period, and location had an interaction with treatments (Table 7). Mean total soil $\mathrm{N}$ for all treatments for both sites did not significantly differ from each other in Aug. 2016. Most treatments resulted in an increase in total $\mathrm{N}$ from Aug. 2016 to Feb. 2018, but these increases were not significant. At site 2 , the husk plus biochar treatment resulted in lower total $\mathrm{N}$ than did the wood chip treatment in Feb. 2018 (Table 7). The only treatment with decreased total $\mathrm{N}$ was the husk plus biochar treatment at site 2 , with a reduction of $-2.38 \%$. The husk plus EM treatment for site 1 resulted in the highest increase in N $(37.5 \%)$, whereas at site 2 the husk had the highest increase (24.44\%). These changes in the plots with husk plus biochar, husk plus EM, husk, and wood chip treatments were not statistically significant. Soil $\mathrm{N}$ data were also split by sampling location and sampling date to determine if there were changes in soil $\mathrm{N}$ in the interrows and rows for the soil profiling treatments (Fig. 3). Soil N was higher in the rows of trees $(4.60 \%)$ before soil profiling compared with that in the interrows (3.55\%). After soil profiling occurred and soil from the interrow was displaced in the rows, soil $\mathrm{N}$ concentrations at these two sampling locations were more similar. At the end of the study, both the interrow and row soil sampling locations had $4.34 \%$ total N (Fig. 3).

Partial economic analysis. Based on the partial economic analysis (Table 8), husk mulch and wood chip mulch are the cheapest soil amendment options ( $\$ 160.53 / \mathrm{ha})$. The soil profiling treatment is the secondcheapest option ( $\$ 222.50 / \mathrm{ha})$ because it does not have any material costs. The husk plus biochar treatment costs the most $(\$ 422.85 / \mathrm{ha})$ because of the high cost of the biochar product (\$247.11/ha). The husk plus EM treatment costs $\$ 407.66 / \mathrm{ha}$. It takes $6.2 \mathrm{~h}$ to apply EM to 1 ha at the application rate used in this study. The husk mulch resulted in the second highest estimated gross profit per hectare (Table 8). Soil profiling resulted in the highest profit per hectare $(\$ 32,001.08 / \mathrm{ha})$ because of partial cost deductions. The control resulted in the 
Table 6. Mean dry biomass weights of total root, proteoid root, and proportion of proteoid root presence by sampling period and two-way analysis of variance full factorial reports for the significance of effects and interactions for location, month, and treatment for macadamia trees receiving six soil amendment treatments and change from pretreatment to final sampling $(\mathrm{N}=16)$.

\begin{tabular}{|c|c|c|c|c|c|c|c|c|}
\hline \multicolumn{2}{|c|}{ Source of variation ${ }^{z}$} & & & & & & & \\
\hline Location (L) & 0.0574 & \multicolumn{7}{|c|}{ Mean total root mass by volume $(\mathrm{g})$} \\
\hline Month (M) & 0.0007 & Sampling period & Control & Husk & Husk+biochar & Husk+EM & Soil profile & Wood chip \\
\hline Treatment $(\mathrm{T})$ & 0.8258 & Feb. 2017 & $0.25^{\mathrm{NS}}$ & 0.25 & 0.16 & 0.23 & 0.25 & 0.26 \\
\hline $\mathrm{L} * \mathrm{M}$ & 0.9273 & June 2017 & $0.27^{\mathrm{NS}}$ & 0.28 & 0.31 & 0.27 & 0.22 & 0.32 \\
\hline $\mathrm{L}^{*} \mathrm{~T}$ & 0.0072 & Feb. $2018^{z}$ & $0.27^{\mathrm{ab}}$ & $0.31^{\mathrm{ab}}$ & $0.37^{\mathrm{ab}}$ & $0.43^{\mathrm{a}}$ & $0.37^{\mathrm{ab}}$ & $0.22^{\mathrm{b}}$ \\
\hline $\mathrm{M}^{*} \mathrm{~T}$ & 0.0390 & Change $^{\mathrm{y}}$ & +0.02 & +0.06 & +0.21 & +0.20 & +0.12 & -0.04 \\
\hline $\mathrm{L} * \mathrm{M} * \mathrm{~T}$ & 0.7354 & Change (\%) & 8.00 & 24.00 & 131.25 & 86.95 & 48.00 & -15.38 \\
\hline Location (L) & 0.4243 & \multicolumn{7}{|c|}{ Mean proteoid root weight by volume (mg) } \\
\hline Month (M) & $<0.0001$ & & Control & Husk & Husk+biochar & Husk+EM & Soil profile & Wood chip \\
\hline Treatment $(\mathrm{T})$ & $<0.0001$ & Feb. 2017 & $2.0^{\mathrm{NS}}$ & 3.2 & 1.6 & 2.6 & 3.6 & 10.5 \\
\hline $\mathrm{L}^{*} \mathrm{M}$ & 0.3453 & June 2017 & $3.4^{\mathrm{NS}}$ & 7.6 & 0.0 & 7.9 & 15.2 & 8.5 \\
\hline $\mathrm{L}^{*} \mathrm{~T}$ & 0.7456 & Feb. 2018 & $2.6^{\mathrm{a}}$ & $22.2^{\mathrm{a}}$ & $20.9^{\mathrm{a}}$ & $156.3^{\mathrm{b}}$ & $18.3^{\mathrm{a}}$ & $2.1^{\mathrm{a}}$ \\
\hline $\mathrm{M}^{* \mathrm{~T}}$ & $<0.0001$ & Change & +0.6 & +19.0 & +19.3 & +153.7 & +14.7 & -8.4 \\
\hline $\mathrm{L}^{*} \mathrm{M} * \mathrm{~T}$ & 0.3642 & Change (\%) & 30.00 & 593.75 & $1,206.25$ & $5,911.53$ & 408.33 & -80.00 \\
\hline Location (L) & 0.5855 & \multicolumn{7}{|c|}{ Proportion of samples with proteoid roots $(\%)$} \\
\hline Month (M) & 0.1266 & & Control & Husk & Husk+biochar & Husk+EM & Soil profile & Wood chip \\
\hline Treatment (T) & 0.0001 & Feb. 2017 & $18.8^{\mathrm{NS}}$ & 25.0 & 12.5 & 31.3 & 31.3 & 43.8 \\
\hline $\mathrm{L}^{*} \mathrm{M}$ & 0.964 & June 2017 & $25.0^{\mathrm{NS}}$ & 31.3 & 0 & 25.0 & 43.8 & 37.5 \\
\hline $\mathrm{L}^{*} \mathrm{~T}$ & 0.2912 & Feb. 2018 & $6.3^{\mathrm{c}}$ & $43.8^{\mathrm{bc}}$ & $25.0^{\mathrm{bc}}$ & $87.5^{\mathrm{a}}$ & $50.0^{\mathrm{ab}}$ & $12.5^{\mathrm{bc}}$ \\
\hline $\mathrm{M}^{*} \mathrm{~T}$ & 0.001 & Change & -12.5 & +18.8 & +12.5 & +56.2 & +18.7 & -31.3 \\
\hline $\mathrm{L}^{*} \mathrm{M} * \mathrm{~T}$ & 0.3651 & Change (\%) & -66.48 & 75.20 & 100.00 & 179.55 & 59.74 & 71.46 \\
\hline
\end{tabular}

${ }^{\mathrm{z}}$ Mean separation by the Tukey's honestly significant difference method $(P=0.05)$. Data are separated by response variable, and means in the same row in the same response variable with the matching letter(s) are not significantly different. NS = no significant difference found among treatments.

${ }^{\mathrm{y}}$ Bold text indicates a statistically significant difference, with $P \leq 0.05$ between Feb. 2017 and Feb. 2018.

$\mathrm{EM}=$ effective microorganisms.

Table 7. Mean Soil N concentrations (\%) by sampling period and two-way analysis of variance full factorial reports for the significance of effects and interactions for location, month, and treatment for soil under macadamia trees receiving six soil amendment treatments and change from pretreatment to final sampling.

\begin{tabular}{lr}
\hline Source of variation & \\
\hline Location (L) & 0.1807 \\
Month (M) & $<\mathbf{0 . 0 0 0 1}$ \\
Treatment (T) & 0.0962 \\
L*M & 0.2288 \\
L*T & $\mathbf{0 . 0 0 8 0}$ \\
M T $^{*}$ & 0.0678 \\
L $^{*} \mathrm{~T}$ & 0.4383
\end{tabular}

\begin{tabular}{|c|c|c|c|c|c|c|}
\hline \multicolumn{7}{|c|}{ Site 1} \\
\hline Sampling period & Control & Husk & Husk+biochar & Husk+EM1 $^{\mathrm{y}}$ & Soil profile & Wood chip \\
\hline Aug. 2016 & $0.5^{\mathrm{NS}}$ & 0.51 & 0.52 & 0.48 & 0.51 & 0.46 \\
\hline June 2017 & $0.46^{\mathrm{NS}}$ & 0.46 & 0.49 & 0.46 & 0.46 & 0.47 \\
\hline Feb. 2018 & $0.54^{\mathrm{NS}}$ & 0.63 & 0.54 & 0.66 & 0.57 & 0.56 \\
\hline Change $^{x}$ & +0.04 & +0.12 & +0.01 & +0.18 & +0.06 & +0.01 \\
\hline Change (\%) & 8.00 & 23.5 & 1.92 & 37.50 & 11.76 & 2.17 \\
\hline \multicolumn{7}{|c|}{ Site 2} \\
\hline & Control & Husk & Husk+biochar & Husk+EM1 & Soil profile & Wood chip \\
\hline Aug. 2016 & $0.47^{\mathrm{NS}}$ & 0.45 & 0.42 & 0.47 & 0.51 & 0.48 \\
\hline June 2017 & $0.48^{\mathrm{NS}}$ & 0.43 & 0.41 & 0.46 & 0.41 & 0.47 \\
\hline Feb. $2018^{\mathrm{w}}$ & $0.56^{\mathrm{ab}}$ & $0.56^{\mathrm{ab}}$ & $0.41^{\mathrm{a}}$ & $0.50^{\mathrm{ab}}$ & $0.52^{\mathrm{ab}}$ & $0.59^{b}$ \\
\hline Change & +0.09 & +0.11 & -0.01 & +0.03 & +0.01 & +0.11 \\
\hline Change (\%) & 19.14 & 24.44 & 2.38 & 6.38 & 1.96 & 22.91 \\
\hline
\end{tabular}

${ }^{\mathrm{z}}$ Bold text indicates a statistically significant difference, with $P \leq 0.05$.

${ }^{\mathrm{y}}$ Month and month by interactions not applicable to total yield.

${ }^{x}$ Bold text indicates a statistically significant difference, with $P \leq 0.05$ between Aug. 2016 and Feb. 2018.

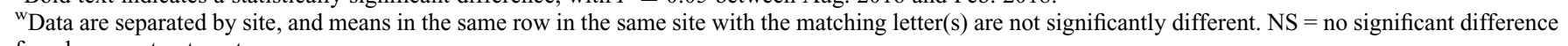
found among treatments.

second-highest partial profit $(\$ 26,656.43 / \mathrm{ha})$, primarily because there were no costs associated with treatment (Table 8).

\section{Discussion}

Yield and quality. Soil profiling is a technique that destructively removes a portion of the soil surface. Macadamia root structures exist very close to the surface of the soil (Firth et al., 2003). The acute destruction of root biomass can cause water stress in plants, which tends to increase the production of abscisic acid (ABA), an endogenous compound that is associated with abscission in plants, including flowers and fruit (Ohkuma et al., 1963). Soil profiling may have had a negative effect on shoot growth through disrupting ABA-ethylene dynamics (Sharp and LeNoble, 2002) while having little effect on yield due to the high density of flowers and the unique ontogenesis of macadamia. The soil profiling treatment occurred in Mar. 2017, during the primary flowering and be- fore fruit development for macadamia. Root pruning may have caused some additional flower abscission, but this most likely did not have a negative effect on yield. Macadamia can produce more than 10,000 racemes with 100 to 300 flowers per raceme; however, generally, only $0.3 \%$ of these flowers develop into fruit (Ito, 1980; Urata, 1954). As long as flowers are not physically removed, the sheer number of flowers can act as a buffer against flower abscission. The root pruning could have affected yield through disrupting the 


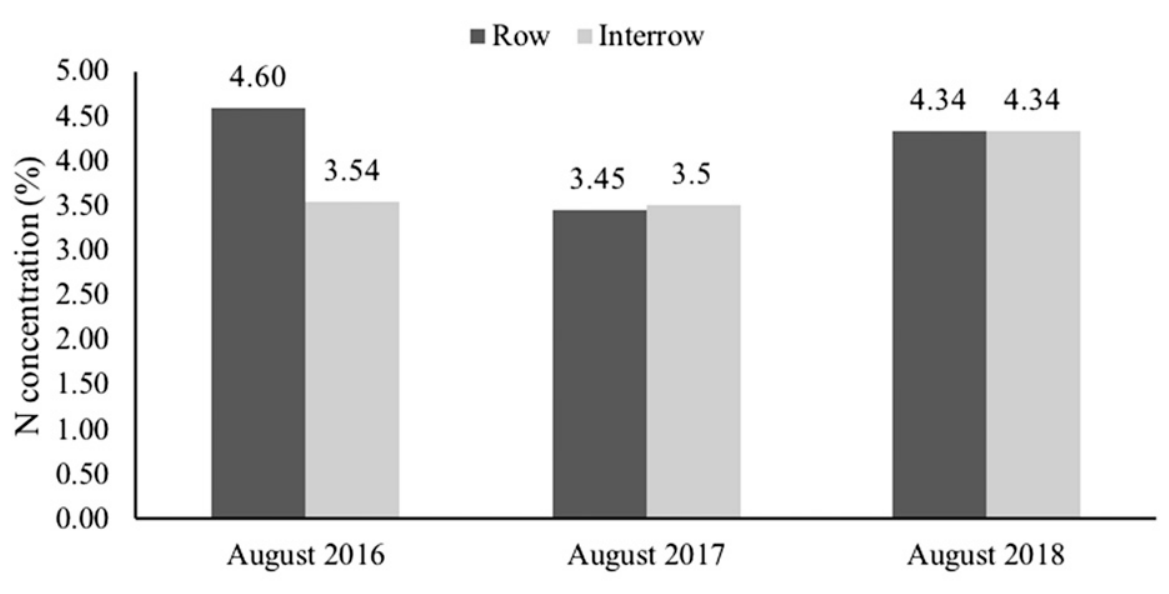

Sampling date

Fig. 3. Mean soil $\mathrm{N}$ concentration averaged by row and interrow sampling location for the soils under macadamia receiving profiling treatments in Kapa'au, HI.

Table 8. Partial cost-benefit analysis showing estimated cost and benefit per hectare for five soil amendment treatments applied in a macadamia orchard in Kapa'au, HI.

\begin{tabular}{|c|c|c|c|c|c|c|}
\hline Application & Husk & Husk+biochar & Husk+EM ${ }^{z}$ & Soil profile & Wood chips & No treatment \\
\hline Material cost/hectare $(\$)$ & 61.78 & 247.11 & 17.30 & 0.00 & 61.78 & 0.00 \\
\hline Labor cost $/ \mathrm{h}(\$)$ & 22.00 & 22.00 & 22.00 & 22.00 & 22.00 & 0.00 \\
\hline Fuel cost $/ \mathrm{h}(\$)$ & 6.50 & 7.00 & 5.75 & 7.50 & 6.50 & 0.00 \\
\hline $\begin{array}{l}\text { Equipment } \\
\text { depreciation/h (\$) }\end{array}$ & 11.00 & 11.00 & 19.50 & 15.00 & 11.00 & 0.00 \\
\hline $\begin{array}{l}\text { Number of hectare } \\
\text { treated/h } \mathrm{h}^{\mathrm{y}}\end{array}$ & 0.40 & 2.63 & 0.16 & 0.20 & 0.40 & 0.00 \\
\hline Cost/hectare (\$) & 160.53 & 262.32 & 247.13 & 222.50 & 160.53 & 0.00 \\
\hline $\begin{array}{c}+ \text { Husk (biochar } \\
\text { and EM) }(\$)^{\mathrm{x}}\end{array}$ & - & 160.53 & 160.53 & . & - & - \\
\hline \multicolumn{7}{|c|}{ Yield benefits } \\
\hline $\begin{array}{l}\text { Estimated wet-in-shell } \\
\text { yield/tree }(\mathrm{kg})\end{array}$ & 43.18 & 41.03 & 40.72 & 53.20 & 37.16 & 41.51 \\
\hline $\begin{array}{l}\text { Estimated yield/ } \\
\text { hectare }(\mathrm{kg})\end{array}$ & $10,348.78$ & $9,834.68$ & $9,761.25$ & $12,752.38$ & $8,906.63$ & $9,950.19$ \\
\hline $\begin{array}{l}\text { KRR adjusted yield/ } \\
\text { hectare }(\mathrm{kg})\end{array}$ & $10,245.30$ & $10,129.72$ & $10,021.54$ & $12,709.87$ & $9,144.14$ & $10,514.04$ \\
\hline Price per kg (2017) (\$) & 2.84 & 2.84 & 2.84 & 2.84 & 2.84 & 2.84 \\
\hline Rever & 975.08 & 682.07 & $25,407.78$ & $32,223.58$ & $23,183.29$ & 556.43 \\
\hline $\begin{array}{l}\text { Profit after deducting } \\
\text { treatment costs }(\$)^{\mathrm{w}}\end{array}$ & $25,814.55$ & $25,259.22$ & $25,000.12$ & $32,001.08$ & $23,022.76$ & $26,656.43$ \\
\hline
\end{tabular}

${ }^{\mathrm{z}}$ Cost/acre for effective microorganisms (EM) treatment based on $2.5 \mathrm{~h}$ of preparation and clean-up and $3.7 \mathrm{~h}$ of application for $1 \mathrm{ha}$. Labor costs are calculated at $6.2 \mathrm{~h}$ and fuel and equipment depreciation are calculated at $3.7 \mathrm{~h}$.

${ }^{\mathrm{y}}$ This number is based on how many hectares can be treated per hour for each treatment. This is based on speed of the equipment and other operating limitations that limit the application efficiency. This is used to adjust labor hours, fuel cost, and equipment depreciation from per hour to per hectare.

${ }^{\mathrm{x}}$ Husk mulch, soil profiling, and wood chip mulch not mixed in combination with husk

${ }^{\mathrm{w}}$ Profit is partially calculated. Only treatment costs are deducted. Complete operating costs are considered the same for all treatments and not included in this partial profit calculation.

competition between vegetative and reproductive growth. The restriction of vegetative growth in apples reduced fruit abscission and increased yield (Quinlan and Preston, 1971). Alternatively, root pruning for apple trees reduced shoot growth but also reduced yield (Mcartney and Belton, 1992). In an experiment involving macadamia, shoot growth that occurred after pruning reduced yield compared with treatments during which these shoots were removed (McFayden et al., 2011). If soil profiling did have a negative effect on shoot growth and did not negatively affect flowering, then it could have caused a larger amount of carbohydrates to be assimilated toward the fruit during development.
Precipitation was relatively low during Summer 2017 (Fig. 4). The highest precipitation levels of the whole study were $198 \mathrm{~mm}$ and $266 \mathrm{~mm}$, and they occurred during Oct. 2017 and Nov. 2017, respectively. These were relatively great amounts of precipitation compared with the total precipitation in June $(1.01 \mathrm{~mm})$, July (7 mm), and August (75 mm). Humidity was also higher during Oct. 2017 (79.1\%) and Nov. 2017 (81.8\%) compared with the summer months (Fig. 5), although the differences in humidity levels were not as drastic as the differences in precipitation between months. Because harvesting times were equally spaced and the nuts from the August harvest time resided in the field the longest, precipitation was the most likely cause of the reduced KRR observed during later harvests. Mold can be a significant issue with the lowering KRR, and excessive moisture exacerbates this issue by promoting mold growth. Excess moisture can also accelerate rancidification (Woodroof, 1979), which is another factor that reduces the KRR. The effect of location on dry kernel weights may be explained by the management practices. Organically grown apples resulted in lower fruit weights compared to their conventionally grown counterparts (do Amarante et al., 2008; Roussos and Gaspartos, 2009). Furthermore, there may be underlying microclimatic differences in sites that are causing this disparity in kernel weight that have not been considered.

$S P A D$ value. Changes in SPAD values are related to changes in leaf $\mathrm{N}$ and chlorophyll content and are affected by $\mathrm{N}$ availability in the soil for orchard crops (Neilsen et al., 1995). The total soil $\mathrm{N}$ data (Table 7) implied that total soil $\mathrm{N}$ did not have the most significant role in changes in SPAD values. Leaf water content can also affect SPAD measurements, with lower leaf water content correlating to higher SPAD values (Martinez and Guiamet, 2004). Time of day is also a potential source of variation in the samples due to a change in leaf water concentration and its effect on SPAD (Chang and Robinson, 2003). Researchers found that organic management in coffee orchards resulted in higher water-holding capacity compared with conventional orchards (Velmourougane, 2016). The increased water-holding capacity in concert with mulch application could result in higher water availability in these treatment plots. The increase in SPAD values in the trees receiving the husk plus EM treatment might be attributed to the increased proteoid root growth on these trees (Table 6).

Root growth. The husk plus EM treatment significantly affected the root growth of macadamia. It was the only treatment to significantly increase total root biomass, proteoid root biomass, and proteoid root initiation. Previous reports suggested that proteoid roots are influenced by microbial inoculation of the soil of macadamia (Malcolm, 1979), and that soil microorganisms are responsible for the formation of proteoid roots in other proteaceous genera (Lamont and McComb, 1974). Proteoid roots also occur in Lupinus species, and their formation requires sugar signaling 


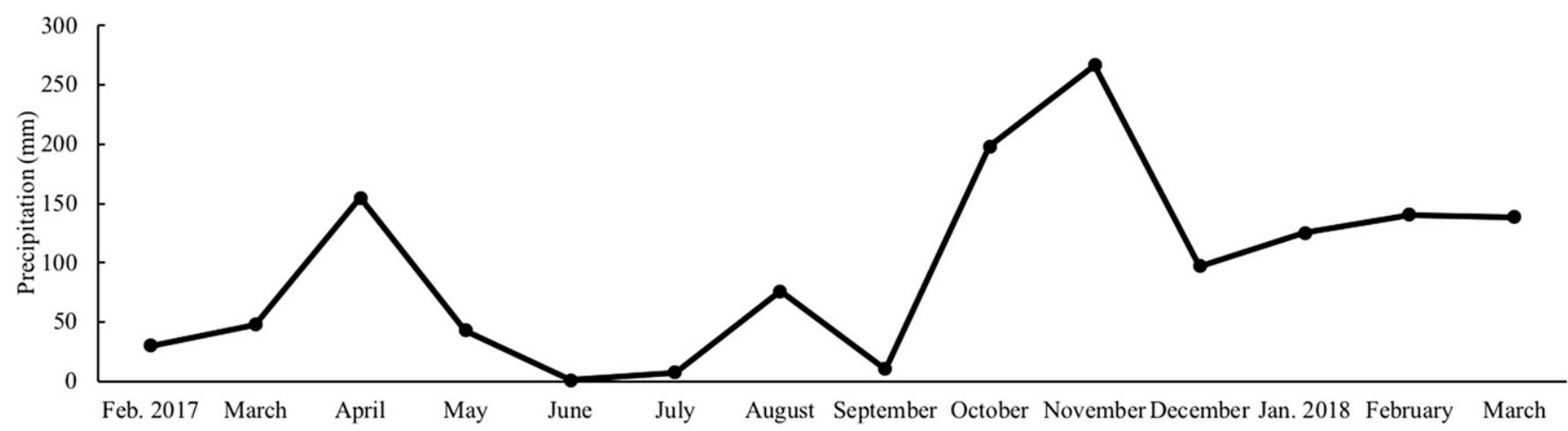

Fig. 4. Total monthly precipitation from Feb. 2017 to Mar. 2018 as collected by a weather station adjacent to experimental sites in Kapa'au, HI.

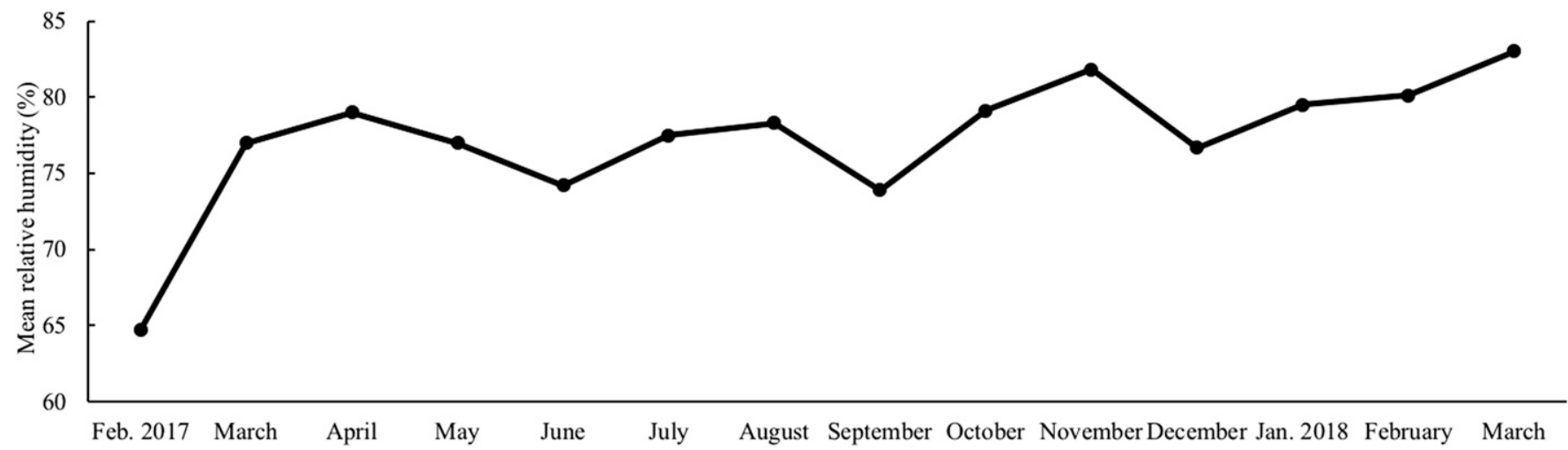

Fig. 5. Mean relative humidity by month from Feb. 2017 to Mar. 2018 as collected by a weather station adjacent to experimental sites in Kapa'au, HI.

(Zhou et al., 2008). Incomplete polysaccharide metabolism and exopolysaccharide production by $L$. casei may have had an effect on sugar availability and, therefore, signaling of proteoid root production in the soils of macadamia orchards. Additionally, the use of molasses as a food source for L. casei may have had the additional effect of providing a sugar source for proteoid root signaling. L. casei has not been identified as one of the microorganisms responsible for the promotion of proteoid roots in macadamia in any available previous study.

Soil nitrogen. Total soil N remained similar from pretreatment to posttreatment for all treatments. The low baseline percentage of $\mathrm{N}$ of all the treatment inputs could have been responsible for this (Table 2). The husk treatments had the highest total $\mathrm{N}$ increases, likely due to the husk having the highest baseline $\mathrm{N}$ concentration (Table 3 ). The husk plus biochar treatment did not substantially increase total $\mathrm{N}$; at site 2 , it was the only treatment to slightly decrease total N. This lack of response from the husk plus biochar treatment could be due to the ability of biochar to alter soil $\mathrm{N}$ dynamics and adsorb $\mathrm{NO}_{3}{ }^{-}$and $\mathrm{NH}_{4}{ }^{+}$(Clough et al., 2013) as it leached from the husk mulch. Due to its C:N ratio of 146:1 (Table 3), the wood chip mulch was expected to decrease total $\mathrm{N}$ through microbial immobilization; however, this did not occur. The difference in the changes in the $\mathrm{N}$ concentration for the wood chip treatment at site $1(+0.01 \%)$ compared with that at site $2(+0.11 \%)$ may be explained by a great deal of research that stated that organic systems have more microbial biomass and activity than conventional systems (Lori et al., 2017), and that this would cause higher $\mathrm{N}$ immobilization. This would only be a reasonable explanation if the $\mathrm{N}$ immobilizing microbes were colonizing the mulch substrate. The soil profiling treatment resulted in patterns similar to those of the control treatment for soil N response variables. Soil profiling was expected to displace nutrient-rich soil from the interrows to the rows. This was not the case, however, and results of separating soil samples showed that there was not a higher $\mathrm{N}$ concentration in the interrows compared with the rows before the soil profiling treatment (Fig. 3).

Partial economic analysis. The husk plus biochar and husk plus EM treatments are the most expensive treatment options because the biochar and EM both were applied separately from the mulch. These costs could be reduced if the additional inputs were combined with the mulch before applying the mulch to the orchards, which would increase the number of hectares treated per hour. Previous studies suggested it may require more than 1 year for yield benefits to become apparent after mulch applications in macadamia orchards (Porter et al., 2005). The benefits of organic agriculture extend beyond yield and include yield stability, biodiversity, soil and water quality, climate change mitigation, and farmer and worker health and quality of life, to a varying degree, all of which are context-dependent (Seufert and Ramankutty, 2017).

This study suggested that soil amendment treatments can affect yield, SPAD values, and root growth of mature macadamia trees within 1 year. Soil profiling was the only treatment to have a higher yield than the control; therefore, it could be explored as a yield-increasing management practice that should be exercised judiciously. It is recommended that long-term effects of repeated soil profiling should be studied. Mulches may cause a short-term reduction in leaf SPAD values in an organic system; however, husk plus EM treatment has the potential to increase SPAD values and, implicitly, leaf tissue $\mathrm{N}$ concentrations in both organic and conventional systems. The increase in SPAD values in trees that received the husk plus EM treatment may be attributed to the increase in proteoid growth in those trees. Compared with all other treatments, husk plus EM treatment increased root growth, especially proteoid root growth. Proteoid roots are very effective for nutrient and water uptake and have the potential to improve the ability of plants to access these resources. Fresh wood chips have the potential to decrease both total 
root growth and proteoid root growth. Economically, soil profiling is the most profitable treatment choice, with a profit of $\$ 32,001 /$ ha after deducting the cost of treatment. The wood chip treatment had the lowest profit of $\$ 23,023 / \mathrm{ha}$. In summary, soil profiling can be a short-term method of improving yield, and husk plus EM treatment can improve leaf $\mathrm{N}$ content and root growth. Husk plus EM is not recommended as a stand-alone treatment with an $\mathrm{N}$ concentration of $1.1 \%$ (Table 3 ). Fresh wood chips had a negative effect on yield, SPAD values, and root growth, and it is not recommended as a soil amendment for macadamia. The relationship between proteoid root growth and changes in leaf $\mathrm{N}$ concentrations is a topic that should be studied to determine if it can improve the nutrient use efficiency of macadamia. The long-term effects of these mulch treatments on macadamia and soil health merit further investigation.

\section{Literature Cited}

Ahmad, A.A., T. Radovich, H.V. Nguyen, J. Uyeda, A. Arakaki, J. Cadby, R. Paull, J. Sugano, and G. Teves. 2016. Use of organic fertilizers to enhance soil fertility, plant growth, and yield in a tropical environment, p. 85-108. In: M.L. Larramendy and S. Soloneski (eds.). Organic Fertilizers-From Basic Concepts to Applied Outcomes. Intechopen. London, U.K. 10 June 2018. <https://www.intechopen. com/books/organic-fertilizers-from-basic-conceptsto-applied-outcomes/use-of-organic-fertilizersto-enhance-soil-fertility-plant-growth-and-yieldin-a-tropical-environmen>.

Allison, F.E. 1973. Soil organic matter and its role in crop production. Elsevier, Amsterdam.

Baiamonte, G., C. Pasquale, V. Marsala, G. Cimo, G. Alonzo, G. Crescimanno, and P. Conte. 2014. Structure alteration of a sandy-clay soil by biochar amendments. J. Soils Sediments 15(4):816-824.

Clough, T.J., L.M. Condron, C. Kammann, and C. Muller. 2013. A review of biochar and soil nitrogen dynamics. Agronomy 3:275-293.

Cox, J., L. Van-zwieten, M. Ayres, and S. Morris. 2004. Macadamia husk compost improves soil health in sub-tropical horticulture. Proc. 3rd Australian New Zealand Soils Conf. Sydney, A.U. 5-9 Dec. 2004.

Chang, S. and D. Robinson. 2003. Nondestructive and rapid estimation of hardwood foliar nitrogen status using the SPAD-503 chlorophyll meter. For. Ecol. Mgt. 181:331-338.

Dalby, T., J. Cox, and S. Morris. 2010. Harvest equipment and soil erosion in a macadamia orchard. Proc. 19th World Congr. of Soil Sci. Brisbane, A.U. 1-6 Aug. 2010.

do Amarante, C.V.T., C.A. Steffens, A. Luiz Mafra, and J.A. Albuquerque. 2008. Yield and fruit quality of apple from conventional and organic production systems. Pesq. Agropec. Bras. Brasilia. 43:333-340.

Environmental Protection Agency. 2016. Climate change indicators in the United States: Atmospheric concentrations of greenhouse gases. 11 Jan. 2018. <https://www.epa.gov/sites/production/ files/2016-08/documents/print_ghg-concentrations2016.pdf $>$.

Firth, D., R. Whalley, and G. Johns. 2003. Distribution and density of the root system of macadamia on krasnozem soil and some effects of legume groundcovers on fibrous root density. Austral. J. Expt. Agr. 43(5):503-514.

Fletcher, A., H. Rennenberg, and S. Schmidt. 2009. Nitrogen partitioning in orchard grown Macadamia integrifolia. Tree Physiol. 30:244-256.

Gao, Y., Y. Li, J. Zhang, W. Liu, Z. Dang, W. Cao, and Q. Qiang. 2009. Effects of mulch, N fertilizer, and plant density on wheat yield, wheat nitrogen uptake, and residual soil nitrate in a dryland area of China. Nutr. Cycl. Agroecosyst. 85(2):109-121.

Giambelluca, T., Q. Chen, A. Frazier, J. Price, Y. Chen, P. Chu, J. Eischeid, and D. Delparte. 2013. Online rainfall atlas of Hawai'i. Bul. Amer. Meteorol. Soc. 94:313-316.

Heisler, J., P. Glibert, J. Burkholder, D. Anderson, W. Cochlan, W. Dennison, C. Gobler, Q. Dortch, C. Heil, E. Humphries, A. Lewitus, R. Magnien, H. Marshall, K. Sellner, D. Stockwell, D. Stoecker, and M. Suddleson. 2008. Eutrophication and harmful algal blooms: A scientific consensus. Harmful Algae 8(1):3-13.

Hirae, H. 1976. Leaf and soil analysis in macadamia. Hawaii Macadamia Producers' Assoc. 16th Annu. Proc. p. 65.

Huett, D.O., B.J. Gogel, M.N. Meyers, C.A McConchie, L.M. McFayden, and S.C. Morris. 2001. Leaf nitrogen and phosphorus levels in macadamias in response to canopy position and light exposure, their potential as leaf-based shading indicators, and implications for diagnostic leaf sampling protocols. Austral. J. Agr. Res. 52:513-522.

Iwaishi, S. 2000. Effect of organic fertilizer and effect of microorganisms on growth, yield and quality of paddy-rice varieties. J. Crop Prod. 3:269-273.

Ito, P. 1980. Effect of style removal on fruit set in macadamia. HortScience 15:520-521.

Jeffery, S., F.F.A. Verheijen, M. van der Velde, and A.C. Bastos. 2011. A quantitative review of the effects of biochar application to soils on crop productivity using meta-analysis. Agr. Ecosyst. Environ. 144:175-187.

Laird, D., P. Fleming, D. Davis, R. Horton, B. Wang, and D. Karlen. 2010. Impact of biochar amendments on the quality of a typical Midwestern agricultural soil. Geoderma 158:443449.

Lamont, B. and A. McComb. 1974. Soil microorganisms and the formation of proteoid roots. Austral. J. Bot. 22(4):681-688.

Liang, B., J. Lehmann, S. Sohi, J. Thies, B. O'Neill, L. Trujillo, J. Gaunt, D. Solomon, J. Grossman, E. Neves, and F. Luizão. 2010. Black carbon affects the cycling of non-black carbon in soil. Org. Geochem. 41:206-213.

Liu, X., S. Herbet, A. Hashemi, X. Zhang, and G. Ding. 2006. Effects of agricultural management on soil organic matter and carbon transformation- a review. Plant Soil Environ. 52: 531-543.

Lori, M., S. Symnaczik, P. Mader, C. De Deyn, and A. Gattinger. 2017. Organic farming enhances soil microbial abundance and activity- A metaanalysis and meta-regression. PLoS One 12(7): E0180442, doi: 10.1371/journal.pone.0180442.

Malcolm, H. 1979. Proteoid roots help macadamia nut trees. Ag. Gazette of New South Wales. 90(1): $42-43$.

Martinez, D. and J. Guiamet. 2004. Distortion of the SPAD-502 chlorophyll meter readings by changes in irradiance and leaf water status. Agronomie 24(1):41-46.

Mcartney, S. and R. Belton. 1992. Apple shoot growth and cropping responses to root pruning. N. Z. J. Crop Hort. Sci. 20:383-390.
McFayden, L., D. Robertson, M. Sedgley, P. Kristiansen, and T. Olesen. 2011. Postpruning shoot growth increases fruit abscission and reduces stem carbohydrates and yield in macadamia. Ann. Bot. 107(6):993-1001.

Nagao, M. and H. Hirae. 1992. Macadamia: Cultivation and physiology. Crit. Rev. Plant Sci. 10(5):441-470.

Neilsen, D., J.H. Eugene, G.H. Neilsen, and P. Parchomchuk. 1995. Using SPAD-502 values to assess the nitrogen status of apple tree. HortScience 30:508-512.

Ohkuma, K., J. Lyon, and F. Addicott. 1963. Abscisin II, an abscission-accelerating substance from young cotton fruit. Science 142:1592-1593.

Olle, M. and I. Williams. 2013. Effective microorganisms and their influence on vegetable production - a review. J. Hort. Sci. Biotechnol. 88(4):380-386.

Porter, G., R. Yost, and M. Nagao. 2005. The application of macadamia nut husk and shell mulch to mature macadamia integrifolia to improve yields, increase nutrient utilization, and reduce soil P levels. Proc. Western Nutr. Mgt. Conf. 6:226-233.

Quinlan, J. and A. Preston. 1971. The influence of shoot competition on fruit retention and cropping of apple trees. J. Hort. Sci. Biotechnol. 46:525-534.

Radovich, T.J.K., L.J. Cox, and J.R. Hollyer. 2009. Overview of organic food crop systems in Hawai'i. College of Tropical Agriculture and Human Resources. SA-3.

Raviv, M. 1998. Horticultural uses of composted material. Acta Hort. 469:225-234.

Reeves, D. 1997. The role of soil organic matter in maintaining soil quality in continuous cropping systems. Soil Tillage Res. 43:131-167.

Roussos, P. and D. Gaspartos. 2009. Apple tree growth and overall fruit quality under organic and conventional orchard management. Scientia Hort. 123(2):247-252.

Seufert, V. and N. Ramankutty. 2017. Many shades of gray- The context-dependent performance of organic agriculture. Sci. Adv. 3:1-14.

Sharp, R. and M. LeNoble. 2002. ABA, ethylene and the control of shoot and root growth under water stress. J. Expt. Bot. 53(366):33-37.

Smith, M., B. Carroll, and B. Cheary. 2000. Mulch improves pecan tree growth during orchard establishment. HortScience 35:192-195.

Stephenson, R. and B.W. Cull. 1986. Flushing patterns of macadamia trees in south east Queensland. Acta Hort. 175:49-53.

Stephenson, R. and E.C. Gallagher. 1989. Timing of nitrogen application to Macadamias. E. Reproductive growth, yield and quality. Austral. J. Expt. Agr. 29:581-585.

United States Department of Agriculture. 2017. Noncitrus fruits and nuts 2017 summary. USDA, National Agricultural Statistics Service. 21 July 2017 . <https://www.nass.usda. gov/Publications/Todays_Reports/reports/ ncit0617.pdf>

United States Department of Agriculture. 2018. Pacific region - Hawaii macadamia nuts final season estimates. National Agricultural Statistics Service. 27 Aug. 2018. <https://www.nass. usda.gov/Statistics_by_State/Hawaii/Publications/ Fruits_and_Nuts/072018MacNutFinal.pdf $>$.

Urata, U. 1954. Pollination requirements of macadamia. Hawaiian Agricultural Experiment Station Technical Bulletin. No. 22.

Velmourougane, K. 2016. Impact of organic and conventional systems of coffee farming on soil properties and culturable microbial diversity. Scientifica. 1 June 2018. <http://dx.doi.org/ 10.1155/2016/3604026>. 
Wall, M. and S.G. Gentry. 2007. Carbohydrate composition and color development during drying and roasting of macadamia nuts (Macadamia integrifolia). ScienceDirect. 40:587-593.

Woodroof, J.G. 1979. Tree nuts: Production, processing, products, 2nd ed. AVI Publisher, Westport.
Xue, N., S. Weiling, Z. Huanchao, Y. Xiulian, and W. Lianggui. 2016. Effects of mulching on soil properties and growth of tea olive (Osmanthus fragrans). PLoS One 11(8):1-11.

Zheng, H., Z. Wang, X. Deng, J. Zhao, Y. Luo, J. Novak, S. Herbert, and B. Xing. 2013. Characteristics and nutrient values of biochars produced from giant reed at different temperatures. Bioresour. Technol. 130:463-471.

Zhou, K., M. Yamagishi, M. Osaki, and K. Masuda. 2008. Sugar signaling mediates cluster root formation and phosphorous starvationinduced gene expression in white lupin. J. Expt. Bot. 59(10):2749-2756. 